\title{
Narrativas inquietantes do horror contemporâneo: 0 estranhamento em Haneke e Lynch
}

\author{
Rogério Ferraraz ${ }^{1}$ \\ Gabriel Perrone ${ }^{2}$ \\ Universidade Anhembi Morumbi
}

\section{Resumo}

O objetivo deste artigo é investigar o estranhamento no horror contemporâneo através da análise de duas obras audiovisuais que se inserem nesse contexto: o longa-metragem O tempo do lobo (Le temps du loup, 2003), de Michael Haneke, e a série televisiva Twin Peaks: O Retorno (Twin Peaks: the return, 2017), de David Lynch e Mark Frost. Distintas em diversos aspectos estilísticos, estéticos e narrativos, tais obras se aproximam ao situar suas histórias no ambiente familiar e reconhecível, porém insólito e desconcertante, tornando-se, assim, propícias ao estudo comparativo em correlação ao conceito de inquietante (ou estranho) proposto por Sigmund Freud.

\section{Palavras-chave}

Horror; Inquietante; Haneke; Lynch; Freud.

\section{Do estranhamento ao horror}

\begin{abstract}
A meta do gênero do horror (...) consiste em exibir, descobrir e manifestar aquilo que é, supostamente em princípio, desconhecido e não cognoscível. Não pode ser acidental o fato de que os enredos caracteristicamente mobilizados para motivar esse momento de inevitável reconhecimento estejam preocupados em mostrar que,
\end{abstract}

\footnotetext{
1 Rogério Ferraraz é docente permanente e Gabriel Perrone é doutorando do Programa de Pós-graduação em Comunicação da Universidade Anhembi Morumbi (SP). roferraraz@hotmail.com

2 Gabriel Perrone é doutorando do Programa de Pós-Graduação em Comunicação da Universidade Anhembi Morumbi. gabrielperrone@gmail.com
} 
na ficção, o que é desconhecido é conhecido ou se tornou, como o enredo sugere, inegável. Tornar conhecido o desconhecido é, de fato, a meta de tais enredos (CARROL, 1999, p. 183).

Há filmes cujos gatilhos para as situações de aversão podem ser uma entidade monstruosa, um espectro malígno, uma visão sobrenatural, elementos que se servem do susto como reação mais imediata. Entretanto, há também aqueles que trabalham o horror, implantando uma ideia ou pensamento na mente do espectador e, muitas vezes, intencionam que esse espectador leve os medos sentidos para além da sala de projeção, para além do término do filme. Então, a emoção produzida nesses casos está mais relacionada a uma certa ameaça em nível psicológico à integridade psíquica, e até mesmo moral, um ataque ao racional, ao estado natural e confortável do que se é familiar. Quando o espectador, em uma mínima identificação com o protagonista da obra, é colocado em conflito com elementos desconhecidos, dos quais ele não identifica suas origens, motivações, explicações, que garantam uma lógica, cria-se a atmosfera do estranhamento e, desse estado, a base propícia para o medo (LOSILLA, 1993).

Ao passo que os filmes de horror sobrenaturais se apoiam nas figuras das criaturas extraordinárias, o terror psicológico aporta na psique, nas ações do homem e todo seu catálogo de medos contemporâneos em relação ao que lhe causa estranheza (LOSILLA, 1993, p. 87 - Tradução dos autores). ${ }^{3}$

Em relação consonante ao estranhamento proposto por Sigmund Freud em seu ensaio O inquietante (Das unheimlich), de 1919, o presente artigo tem como objetivo a análise de duas obras audiovisuais que se inserem no contexto do horror contemporâneo: o longa-metragem O tempo do lobo (Le temps du loup, 2003), de Michael Haneke, e a série televisiva Twin Peaks: O Retorno (Twin Peaks: the return, 2017), de David Lynch e Mark Frost. Distintas em diversos aspectos estilísticos, estéticos e narrativos, tais obras se aproximam ao situar suas histórias no ambiente familiar e reconhecível, porém insólito e desconcertante, tornando-se, assim, propícias ao estudo comparativo em correlação ao conceito de inquietante (ou estranho) proposto por Sigmund Freud, a fim de identificar artifícios e estratégias de elaboração que as definem como obras em que o horror se apresenta pela angústia a um clima de incertezas em que o espectador é envolvido.

O ensaio de Freud oferece muitas indicações para a compreensão de uma estética da estranheza, que merecem ser exploradas para a análise de obras que

3 Do original: "Mientras que las películas de horror sobrenaturales se apoyan en las figuras de las criaturas extraordinarias, el terror psicológico aporta en la psique, en las acciones del hombre y todo su catálogo de miedos contemporáneos en relación a lo que le causa extrañeza.." 
se inserem nesse campo do terror psicológico gerado pelo estranhamento ou pelo inquietante. Para o autor, o estranho se contrapõe ao doméstico, o próximo, o costumeiro, podendo ser lido como impressões sensoriais e experiências que, ao longo do tempo, foram atribuídas ao sentimento de inquietude ante o desconhecido: "A estranheza seria esse tipo de sensação de medo que afeta as coisas familiares por algum tempo" (FREUD, 2010, p. 269). Freud analisa o mal-estar como resultado de uma ruptura na racionalidade tranquilizadora da vida quotidiana, sendo essa ruptura o objeto estranho ou sinistro. Em sua análise sobre o texto, Eugênio Trías define:

Tendo permanecido em segredo, foi revelado. É, portanto, algo que talvez fosse familiar e se tornou estranho e inóspito. Algo que, quando revelado, é mostrado em sua face sinistra, apesar de ser, ou precisamente porque é, na realidade, em profundidade, muito íntimo (TRÍAS, 2001, p. 39 - Tradução dos autores). ${ }^{4}$

O conceito freudiano contribui para o entendimento do medo no gênero em seu teor psicológico como uma mistura de mistério e angústia, sendo estes os objetos sinistros ou estranhos catalizadores. O mistério convida o indivíduo a desvendar os enigmas da história e a angústia, como quota psicológica resultante do suspense extenuante, exige a especulação inquieta das pistas na tentativa constante de retorno ao ambiente familiar.

\section{Haneke, a ruína doméstica e o retorno do primitivo}

Prestes a inteirar trinta anos de carreira na realização cinematográfica, Michael Haneke é um dos mais apreciados e estimados diretores em atividade do cinema europeu e possui lugar de notoriedade e aclamação da crítica e do público. Suas histórias costumam narrar o desmoronar das estruturas sociais burguesas quando colocadas em situações em que o cômodo esperado é ameaçado, surgindo daí os estados de estranhamento, inquietude e caos, nessa mesma ordem, e as falhas de indivíduos alienados que os reconfiguram em serem facilmente propensos a estados que beiram o selvagem. Culturamente, essas narrativas promovem a reflexão inquietante sobre a política de identidade do sistema de classes, sobretudo, o europeu, os papéis de gênero e as hierarquias étnicas, bem como a culpa individual e coletiva que essas estruturas engendram. São, consequentemente, denúncias das fragilidades das intituições, sejam elas familiares, religiosas, trabalhistas, em suma, sociais, que insistem em se mostrar e se autoconvencer como sólidos e indestrutíveis pi-

4 Do original: "Habiendo permanecido en secreto, fue revelado. Es, por lo tanto, algo que quizás fuera familiar y se hizo extraño e inhóspito. Algo que, cuando es revelado, se muestra en su rostro siniestro, a pesar de ser, o precisamente porque es, en realidad, en profundidad, muy íntimo.." 
lares da civilização. As formas dessa narrativa tendem para o episódico, a história muitas vezes apresenta situações ou acontecimentos isolados, independentes, que nem sempre possuem funções para o desenvolvimento sequencial dela, mas, sim, para a composição de um panorama ou contexto. Assim como, tendem também ao elíptico, no qual os resultados das ações das personagens, resultados das suas prepotências, as fazem voltar ao ponto de partida, demonstrando a falta de habilidade para solucionar os problemas criados por elas mesmas, um labirinto perturbador que cresce à medida que repetem os mesmos erros ao não se submeterem à autocrítica (FREY, 2010). As motivações dessas personagens permanecem obscuras; e seus objetivos, ambíguos. São características do diretor a incerteza sobre as origens dos conflitos que geralmente aborda e a estranheza ante o não oferecimento de nunhuma explicação sobre as causas dos eventos que se desenrolam em seus filmes. Assim acontece em O tempo do lobo.

A história se inicia com Georges Laurent (Daniel Duval), sua esposa Anne (Isabelle Huppert) e seus filhos Eva (Anaïs Demoustier) e Ben (Lucas Biscombe) chegando à casa de campo familiar, fugindo da cidade grande. Nenhuma informação é dada sobre o motivo que os fizeram se refugiar. Guerra? Doença infecciosa? De certo modo, isso não se faz relevante; ao contrário, provoca o estranhamento ante o mistério e a ansiedade inquietante e constante de que, em algum momento, algo possa elucidar a situação. O que é dado ao espectador é uma sensação de que as estruturas da civilização foram quebradas. Os Laurent encontram uma família invasora em posse da casa, e, no confronto que se segue, Georges é baleado e morto. Haneke, como de costume, não permite o prazer de visualizar o homicídio, de se assistir a violência explícita, algo que o cinema tradicional não perderia a chance de exibir. Se Freud trata como estranho e angustiante o rompimento do que é familiar ou doméstico, no filme, logo de início, o espectador é jogado à situação das personagens de perda do ambiente doméstico após invasão da casa de campo da família, que lá iria se refugiar, e à ameaça da estrutura familiar com a execução do pai pelos invasores. No jogo proposto pelo realizador, pode-se identificar como estratégia de construção do horror diversos fatores que causam a estranheza e inquietude semelhantes aos encontrados por Freud em sua análise do conto de horror O homem de areia, de Hoffmann. ${ }^{5}$

5 Para exemplificar o que seria o inquietante, ligado aos elementos conhecidos e familiares, Freud utilizou-se do conto $\mathrm{O}$ homem da areia, do escritor alemão E.T.A. Hoffmann, um dos principais nomes do romantismo alemão. A história original do Homem da Areia era um conto infantil para crianças que não queriam dormir. O Homem da Areia seria a figura responsável por soprar areia nos olhos delas para fazê-las fechar os olhos, dormir e sonhar - sonhos agradáveis ou não. O conto de Hoffmann confere a tal figura aspectos aterrorizantes: tratar-se-ia de um homem mau, que jogava areia nos olhos das crianças quando elas se recusavam a ir dormir; os olhos, então, saltariam sangrando da cabeça, ele os recolheria e os levaria para a Lua, para alimentar seus filhotes, que teriam bicos retorcidos como corujas. 


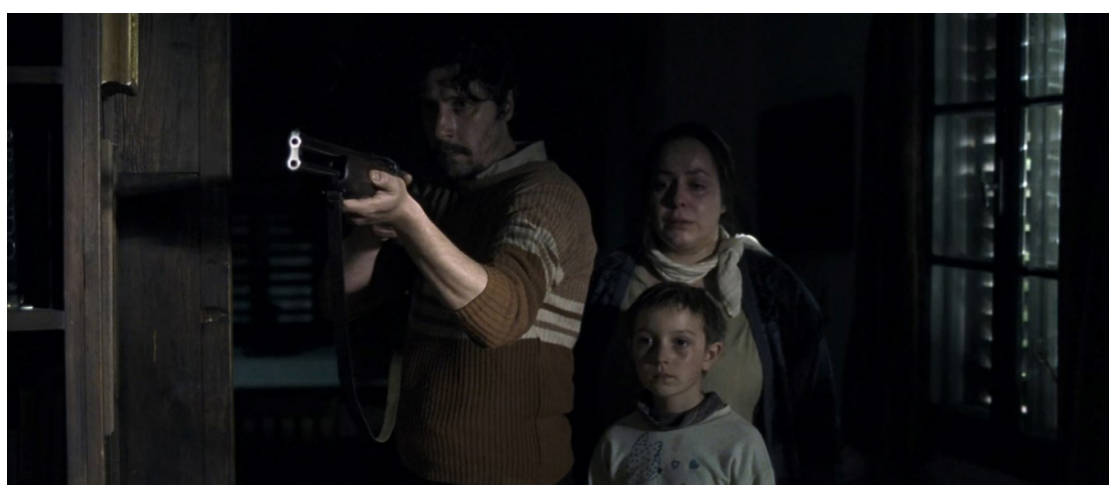

Figura 1: A família invasora

Fonte: Arte France Cinéma

A começar, a história de Haneke se desenvolve num ambiente pós-apocalíptico de causas desconhecidas para o espectador, mas conhecidas para as personagens, como podemos ver na cena em que Anne com seus dois filhos pedem ajuda a um vizinho, apelando pela sua humanidade:

- Mas é seu dever nos ajudar!

- Sabe muito bem qual é a situação. Age como se não soubesse.

A falta dessa informação já gera no espectador um estado de angústia e cria a expectativa constante de tentar descobrir o motivo do caos. A partir daí, ambos, personagens e espectador, se encontram na situação de incerteza ante os acontecimentos que irão se suceder e às personagens que irão encontrar. Entretanto, tudo nos leva a acreditar que a causa do cataclisma é consequência das próprias ações humanas. Seja como uma punição sobrenatural, da ação de uma força superior, ou da destruição das condições naturais de sobrevivência, a desconfiança recai sobre homem em estado de retorno a um comportamento selvagem, a inversão da ordem que o fez civilizado. Assim como o vizinho de Anne que nega o socorro e rompe com a conduta moralmente esperada, lembramo-nos que os invasores da casa são, ainda que cruéis, uma família - um pai, uma mãe e um filho criança - o que nos faz retornar à questão já abordada de que o inquietante reside no familiar.

Quase sem posses e sem ajuda, a família inicia uma jornada de busca de abrigo. O primeiro encontrado é um celeiro no vazio de um pasto que beira um desolado infinito. Durante a noite, Eva acorda a mãe ao perceber que Ben não está presente e começam uma procura pelo menino em meio à escuridão quase total, o 
que se torna um dos motivos visuais desse trecho do filme. Anne se afasta em busca do filho com o auxílio de apenas um isqueiro, enquanto Eva permanece no celeiro, queimando punhados de feno para que a mãe consiga se situar e encontrar o caminho de volta. Haneke filma toda sequência com realismo absoluto ao optar pela não utilização de iluminação artificial, que nos leva ao realismo de Bazin em Uma estética da realidade: em vez de usar a montagem para fixar a atenção do espectador, “(...) é a mente do espectador que é forçada a discernir (...) o espectro dramático próprio da cena” (BAZIN, 2004, p. 28 - Tradução dos autores) ${ }^{6}$. Com o afastamento de Anne, a pequena chama é o único e minúsculo ponto de luz que falha constantemente, deixando a cena em longos períodos de total escuridão. Em um nível, é a representação realista de um mundo sem eletricidade, mas, em outro nível, mais estratégico, é a expressão da atmosfera de medo, incerteza e vulnerabilidade. E, para o público, em um nível mais estético, é uma experiência visual intensa do inquietante.

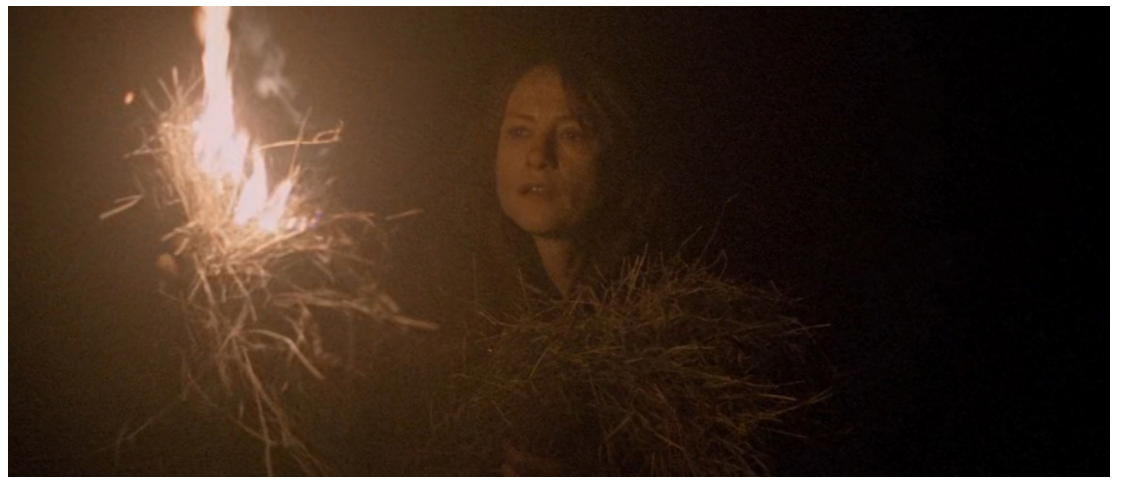

Figura 2: Anne à procura de Ben

Fonte: Arte France Cinéma

Ben é encontrado junto a um adolescente sem nome (Hakim Taleb) e que assim permanecerá até o fim do filme. Num vagar sem rumo e aparentemente sem motivação, a família poderia estar em qualquer lugar, o mais importante - e mais alienamente destrutivo - é a dialética entre o anonimato e a identidade. Vastos campos em grandes planos abertos onde a paisagem natural é destacada e personagens aparecem como pequenos elementos na tela transmitem graficamente um cenário no qual a natureza governa. Sequências são encenadas em longas tomadas que majoritariamente privilegiam os planos estáticos. As composições produzem uma atmosfera de estranhamento devido a um clima ambíguo: num momento de catástrofe ambiental, a França é tranformada, figurativamente, em romântica. Ao mesmo tempo em que os indivíduos sofrem com a falta de alimentos, a fome, se maltratam e se matam, a natureza circundante retém uma beleza de majestade pas-

6 Do original:"(...) it is the mind of the spectator which is forced to discern (...) the dramatic spectrum proper to the scene.". 
toral e pacífica. Padrões específicos de montagem, enquadramento, design de som produzem efeitos que, na melhor das hipóteses, convidam a uma atitude crítica em relação à realidade retratada. Haneke usa de maneira muito própria tais elementos de construção do filme como como sua marca autoral.

Durante o percurso que se segue, o adolescente desconhecido se revela mais familiar à situação, age com um comportamento instintivo de autopreservação selvagem e anula qualquer pudor digno de uma conduta social sofisticada ao encontrar um cadáver e rapidamente vasculhá-lo em busca de objetos e roupas. Revira um cordeiro morto para verificar se é possível servir de alimento. Ao explicar a morte do animal, fala sobre os cães errantes, antes domésticos, agora selvagens por não terem o que comer. Algo que serve como justificativa e metáfora à sua própria transformação.

\section{- Os cães não têm o que comer. É natural.}

Esse pequeno grupo, Anne, seus filhos e o garoto anônimo, adiante, se junta a outro grupo maior, uma comunidade recém-formada de sobreviventes que vivem em uma estação férrea abandonada, esperando por um trem que possa salvá-los. Nessa jovem comunidade, organizada por um líder autoproclamado, Sr. Koslowski (Olivier Gournet), tudo deve ser adiquirido pela troca por bens ou serviços, incluindo favores sexuais das mulheres. A vida nesse vestígio de mundo civilizado é de subsistência básica, rudimentar, cotidiana e muitas vezes cruel. O tempo do lobo é uma espécie de exploração de retirada de todos os recursos que garantem o conforto social a fim de descobrir exatamente o que é que torna a existência de uma sociedade possível em estado de estranheza diante às perdas. Nesse ambiente onde reina a inquietude, Haneke imagina um universo sem ordem coercitiva, cada indivíduo vai tentar tirar o que pode para sua própria sobrevivência ou ganhar sem nenhum senso de princípios ou justiça. Entretanto, emerge o conceito de que ninguém pode existir por conta própria, ninguém é autossuficiente. Logo fica claro que o acordo social e o conluio é uma maneira mais útil de garantir a sobrevivência bem-sucedida do que o esforço individual. A transformação desses europeus de origens diversas, até então civilizados, em uma tribo de selvagens primitivos é apresentada tanto como natural quanto terrível. Durante toda a história, o retorno do instintivo como simples aceitação das circunstâncias que o legitimam é retratado nas diversas relações entre as personagens.

(...) o elemento angustiante é algo reprimido que retorna. Tal espécie de coisa angustiante seria justamente o inquietante (...) O vínculo com a repressão também nos esclarece agora a definição de Schelling, segundo a qual o inquietante é algo que deveria permanecer oculto, mas apareceu (FREUD, 2010, p. 360).

Em uma das noites, Eva assiste, entre a massa de corpos adormecidos ao 
seu redor, a cena de um estupro brutal sem que possa fazer nada além de se jogar sobre o irmão adormecido para protegê-lo de ver a barbárie. A esperança da menina se mantém na crença da amizade com o adolescente selvagem e solitário, que logo abandona o coletivo rudimentar em ato de rebeldia quando todos se voltam contra ele ao o acusarem de roubo. O garoto se afasta para o interior da floresta próxima e lá recebe as visitas regulares de Eva, que cuida do ferimento que ele tem na mão após ser mordido por um dos cães selvagens.

- Eles estão ferozes. Parecia que éramos amigos. Ele me seguiu e então me mordeu.

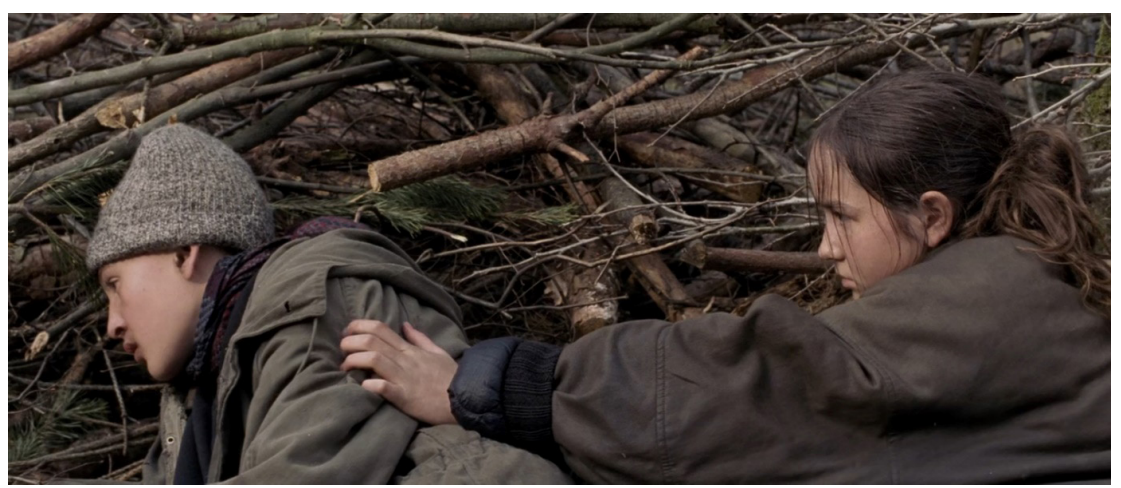

Figura 3:Eva em visita ao adolescente desconhecido na floresta Fonte: Arte France Cinéma

Os cães, no filme, se configuram em verdadeiros lobos. São os animais antes domésticos que têm suas características selvagens de volta, são aquele antes familiar, agora estranho e inquieto, fonte do perigo e do medo. O que nos leva à análise do título da obra em sua tradução correta do original em francês: Os tempos do lobo. A transformação do comportamento pelo rompimento da conduta controlada dos cães é análoga à transformação do caráter das personagens humanas, que, da mesma forma, se reconfiguram como estranhos à medida que revelam suas ações cruéis. Pode-se considerar, então, que os lobos, o que há de selvagem, são os homens nesse ambiente de catástrofe vivido pelas personagens nesses tempos de inquietude, nesses tempos de lobo. Assim, podemos voltar ao cordeiro e concluir que a situação, no filme, justifica o retorno do reprimido, o lado selvagem, pois a sobrevivência está para o lobo e não para o cordeiro, e essa validação que sustenta a narrativa do mundo criado por Haneke se faz como um de seus elementos estruturantes e mais horríveis e assustadores.

Qual é a fonte de toda essa violência? Ela vem da própria existência dos outros e, portanto, da própria concepção de grupo, de família. Embora seja uma 
necessidade, aponta para uma instabilidade dentro do conceito de coletividade em associação às conexões frágeis que unem uns aos outros. Haneke está em plena sintonia aos elementos do estranhamento e do sentimento do inquietante tratados por Freud quando explora o lugar de segurança - o heimlich - como o próprio lugar do perigo - o unheimlicht. Para Haneke, o conceito de casa ou de estrutura familiar está invariavelmente baseado na repressão e numa oculta agressão fundadora, na exploração de outros e na tomada do espaço e de outros como propriedades do fundador. Assim como Freud argumenta que o "simples" esconde um segredo sinistro, o heimlicht do heimlicht, a superfície do modelo civilizado esconde dentro de si um elemento perturbador pronto a ser trazido à luz pelo fato de se manter ali sempre presente, pulsante, à espera de um deslize das ações repressoras para seu ressurgimento. Haneke posiciona relações e estruturas sociais sempre sob ameaça, e essa ameaça sempre está associada à violência e ao horror psicológico da ansiedade constante.

O que fazer de um filme que revela tão pouco de si mesmo? Em entrevistas, Haneke enfatiza sua intenção de deixar o trabalho para a experiência do espectador.

Eu tento fazer filmes com personagens que são menos personagens do que superfícies de projeção para as sensibilidades do espectador; espaços em branco forçam o espectador a trazer seus próprios pensamentos e sentimentos ao filme. Porque é isso que deixa o espectador aberto para a sensibilidade da personagem (DONNER, 2004, p. 35 - Tradução dos autores). ${ }^{7}$

O diretor, em outras palavras, obstrui a explicação com a finalidade de estimular a audiência a pensar e sentir com a obra, em vez de, simplesmente, consumi-la. De fato, propõe uma terapia de choque cinemático.

Meus filmes são declarações contra a subestimação do espectador. É um apelo para um cinema de questionamento e de recusa a respostas dadas ou rápidas. (...) Não se trata de fazer com que o espectador deixe de olhar. Quero que o espectador pense. Mas, às vezes, há realidades que são difíceis de suportar. Quando mostradas de forma dura, pode ser que alguém não aguente. (...) Tem que saber falar das coisas que nos aterrorizam. A violência na sociedade é uma dessas coisas que nos dão medo (VOGEL, 1996, p. 73-75 - Tradução dos autores). ${ }^{8}$

7 Do original: "I try to make films with characters that are less characters than projection surfaces for the viewer's sensibilities; white space forces the viewer to bring their own thoughts and feelings to the film. Because this is what leaves the viewer open to the sensitivity of the character.."

8 Do original:"My films are statements against disempowerment of the spectator. It is an appeal to a cinema 
Amplos espaços e extensões apresentam pouco ou nenhum diálogo, e o silêncio geralmente é abundante; um rigoroso esquema de montagem interrompe essa pausa predominante com súbitas explosões de diálogos e gritos, especialmente durante os conflitos na estação. Na falta de informações explicativas, sobram o uso de informações misteriosas na forma de, por exemplo, alusões culturais (germânicas) que preenchem o espaço em que falta diálogo ou representações visuais diretas, assim como motivos míticos que complementam o vazio informativo. Na estação, um dos refugiados canta Maikäfer flieg, canção popular alemã que narra a história da ocupação e extinção da Pomerânia durante a Guerra dos Trina Anos e, em particular, a necessidade em fugir das cidades em chamas (FRAY, 2010). Além disso, também sobre o título do longa, em tradução direta, "Os tempos do lobo deriva de um verso do poema Völuspá, que integra o manual islandês de poesia escáldica $E d d a$, de Esnorri. O poema descreve o progresso da civilização, as batalhas dos deuses e a destruição do mundo pela guerra" (FRAY, 2010, p. 112-113 - Tradução dos autores $)^{9}$. A $44^{\text {a }}$ estrofe descreve uma passagem do apocalipse:

Irmãos lutarão e matarão uns aos outros, os filhos das irmãs sujarão o parentesco. Isso é duro no mundo, prostituição corrente - uma era de machado, uma era de espada (e o sol surge) - escudos são despedaçados - uma era de vento, uma era de lobo - antes que o mundo vá precipitadamente. Nenhum homem terá misericórdia para com o outro. ${ }^{10}$

A dúvida e o estranhamento que constantemente pairam sobre todos também se revelam de outra forma à desconfiança do ser como cruel. É o caso daquelas personagens que parecem ter um conhecimento especial, místico, que Freud chamou de onipotência do pensamento.

(...) relacionam-se ao princípio que chamei de onipotência do pensamento. (...) A análise de casos do inquietante nos levou à antiga concepção do animismo, que se caracterizava pela superestimação narcísica dos próprios

of questioning and refusal to given answers or fast. (...) It is not about making the viewer stop looking. I want the viewer to think. But sometimes there are realities that are hard to bear. When shown hard, it may be that someone cannot stand it. (...) He must know how to speak of the things that terrify us. Violence in society is one of those things that frighten us.".

9 Do original: "Time of the wolf derives from a verse from the visionary poem "Voluspá", from the Old Icelandic saga Edda. The poem describes the progress of civilization, battles of the gods and the destruction of the world by war.."

10 ESNORRI. Voluspá. In. MOREIRA, Márcio A. A Edda poética: Parte I - Völuspá. Disponível em: <http://portal-dos-mitos.blogspot.com/2014/02/a-edda-poetica-parte-i-voluspa.htm>. Acesso em: 24 nov. 2018. 
processos psíquicos, a onipotência dos pensamentos e a técnica da magia, que nela se baseia, a atribuição de poderes mágicos cuidadosamente graduados a pessoas e coisas estranhas (FREUD, 2010, p. 359).

É o caso de Béa (Brigitte Roüan), uma das personagens que Anne encontra na estação de trem. Inicialmente educada, receptiva, demonstra ser mais civilizada que os demais, mais tarde revela ter pensamentos estranhos ao falar sobre "Os Justos", um grupo seleto cuja missão é salvaguardar a humanidade em momentos de caos. Após a chegada de mais um grupo à estação, um velho senhor (Claude Singeot) elabora mais o tema contando uma história de fogueiras sendo acesas em aldeias onde esses homens santos se atiram nus ao fogo como ato redentor para a salvação da humanidade.

- Eles nos trazem a salvação. Pulam nus dentro das fogueiras e se queimam por nós. Fazem o sacrifício para pôr o mundo em ordem. Existem 36 deles, não? E a missão deles é manter a Terra girando.

Os 36 justos se referem, no aspecto mais místico do judaísmo, à lenda dos 36 homens justos ou santificados cujo papel na vida é justificar a existência da raça humana aos olhos de Deus. Vivendo sobre a Terra, anonimamente, os próprios desconhecem suas condições de justos, são uma espécie de garantia de salvação do mundo perante o julgamento de Deus. É por causa deles que o Criador permite a existência da humanidade, que degenera em barbárie de costumes. Segundo a ciência esotérica hebraica, 36 significa "vida dupla", sendo duplo de 18, que representa "vida". Também são denominados "Justos Ocultos", ou "Santos Ocultos" (CABÚS, 2018). Aqui nos deparamos com uma convergência de vários elementos do estranhamento proposto por Freud. A começar pelo estranhamento que causa a própria informação, que se faz desconhecida pelo espectador. Afinal, qual parcela do público terá conhecimento sobre ciência esotérica hebraica? Também encontramos algo sobre o que Freud fala sobre os duplos:

(...) os mais notáveis entre os temas de efeito inquietante.

(...) São os do "sósia" ou duplo", em todas as suas gradações e desenvolvimentos; isto é, o surgimento de pessoas que, pela aparência igual, devem ser consideradas idênticas, a intensificação desse vínculo pela passagem imediata de processos psíquicos de uma para a outra pessoa (...) de modo que uma possui também o saber, os sentimentos e as vivências da outra; a identificação com uma outra pessoa, de modo a equivocar-se quanto ao próprio EU (FREUD, 2010, p. 351).

Em dois aspectos, temos primeiro o indivíduo de vida dupla, o justo, como 
vimos na significação do número 36 , ao mesmo tempo ser humano e santo, sem ter o conhecimento de ser ambos. E, no segundo aspecto, a conexão psíquica demonstrada por duas personagens que não se conhecem ao trazer uma informação rara, insólita, numa espécie de processo psíquico de transmissão do pensamento, voltamos agora à onipotência do pensamento. E, ainda, serem também chamados de Justos Ocultos, uma característica do ser, nesse caso o de ser santo que se revela, agora, nos direciona, portanto, à questão do oculto já abordado. Haneke parece conhecer bem o ensaio de Freud ao estabelecer esse jogo de imbricações conceituais em harmonia aos princípios lançados pelo pai da psicanálise ao estruturar sua narrativa e mundo ficcional com componentes que se encontram na obra $O$ Inquietante. $\mathrm{O}$ cineasta também é conhecido por promover esses jogos mentais como um quebra-cabeças à espera da sua montagem pelo espectador.

Esses relatos sobre fogueiras e homens que se entregam ao fogo para salvar os outros levam ao poderoso clímax do filme, quando Ben acorda durante a noite com todos seus medos e tensões surgindo de forma representativa com o sangue que escorre de seu nariz e se dirige aos trilhos de trem em meio à escuridão. Ao passar a mão sob o nariz, mancha o roto de sangue e torna a imagem ainda mais dramática. Recolhe galhos e atiça as chamas da fogueira no meio dos trilhos e permanece ali com sua memória, e também a do espectador, ligada aos contos dos sacrifícios no fogo para pôr fim ao caos. Começa a se despir e, quando nu, se inclina em direção ao fogo até que um dos homens se aproxima, percebendo a situação. Ele agarra o garoto de surpresa e o oferece uma visão de otimismo e certo animismo em suas palavras.

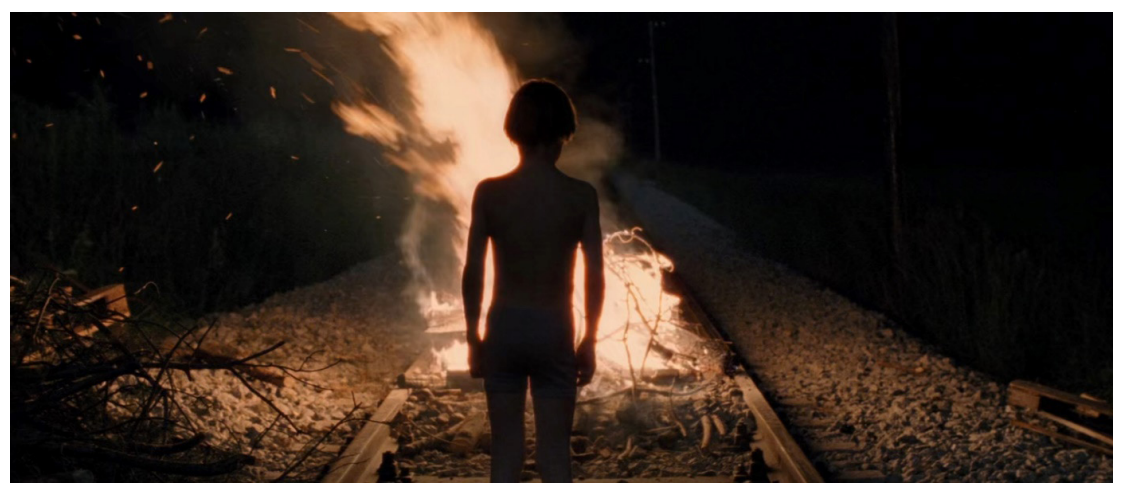

Figura 4: Ben diante da fogueira Fonte: Arte France Cinéma

Então, há o corte brusco para a cena final. Um extraordinário longo take de quase cinco minutos, filmado do interior de um trem, mostrando campos, colinas, 
vales e árvores que correm pela tela, nenhum sinal de humanos, apenas a natureza. Padrões específicos de montagem, enquadramento, design de som produzem uma experiência visual inquietante que, na melhor das hipóteses, convidam a uma atitude crítica em relação à representação da realidade. Sob o som rítmico do ruído do trem, que não é visto no enquadramento, apenas a paisagem exterior, é inevitável as questões no espectador: É o trem que se aproxima com a salvação? As personagens serão salvas? Ou é apenas um trem qualquer em outro qualquer lugar? Seja o que for, é assim que o filme se encerra em corte seco para a tela negra e o silêncio total. $\mathrm{E}$ assim permanece o espectador na sala de cinema por um tempo que parece não ter fim até o início dos créditos finais que preservam a ausência de qualquer som.

Eis a construção do absurdo que fragiliza o público e causa o espanto diante de uma história em que as irracionalidades oportunizam rompantes de violência ou situações infames propícias ao choque, ao constrangimento e ao medo do que pode sempre vir a seguir. A tentativa de compreender a origem do contexto apocalíptico ou ter alguma ideia conclusiva da história se torna uma tarefa fadada ao fracasso, já que o mistério é o que importa e resta ao espectador apenas presumir. "Haneke, essencialmente, não permite quaisquer conclusões, não concede espaço para a autossatisfação do público, exceto, talvez, a pequena satisfação de saber que nenhuma satisfação é possível" (PRICE; RHODES, 2010, p. 120 - Tradução dos autores) ${ }^{11}$. Resoluções narrativas claras são excluídas ou impossíveis de determinar. O cinema de Haneke provoca, denuncia e exige, mas sempre acaba por frustrar a interpretação. A essa frustração, seguem a angústia, o estranhamento e a inquietude no espectador. Nas palavras do diretor, "não existe horror maior do que nos depararmos com quem e como somos" (DONNER, 2004, p. 41 - Tradução dos autores) ${ }^{12}$.

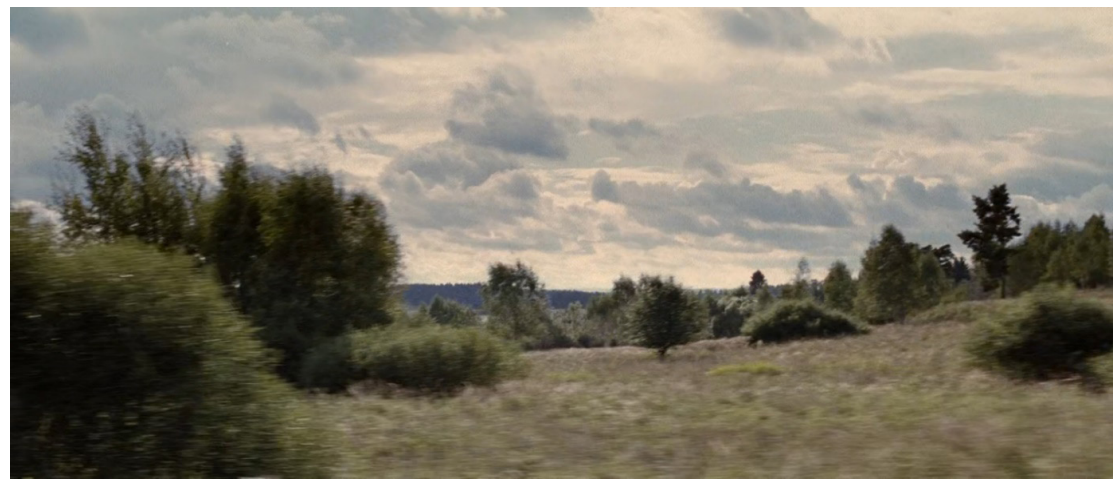

Figura 5: A paisagem vista do trem

Fonte: Arte France Cinéma

11 Do original: "Haneke essentially doesn't allow any conclusions, gives no room for public self-satisfaction except perhaps the small satisfaction of knowing that no satisfaction is possible.".

12 Do original: "There is no greater horror than that of who and what we are.". 
A prática de Haneke e seus retratos chocantes da vida atual são declarações sobre a violência na mídia, as desordens sociais. Podem não ser objetos inovadores de estudo, mas certamente evidenciam um homem que pensa profundamente sobre o cinema como modo de estranhar o público e estimulá-lo aos debates teóricos contemporâneos.

Assim como contemporâneo e instigante é o trabalho de David Lynch, não apenas um cineasta, mas um artista múltiplo, sobre quem muito já se escreveu. A ideia aqui não é recuperar toda sua obra fílmica e televisiva, mas refletir sobre seu último trabalho audiovisual, Twin Peaks: O Retorno, especialmente sua relação com o horror através da presença do inquietante.

\section{Um retorno sinistro e nada nostálgico}

Antes de adentrarmos em Twin Peaks: O Retorno, porém, é necessário voltarmos um pouco no tempo, até o contexto da primeira temporada da série. Em 1990, mesmo ano em que recebeu a Palma de Ouro em Cannes, pelo filme Coração selvagem (Wild at Heart), Lynch criou, em parceria com Mark Frost, a série Twin Peaks. Quando Twin Peaks estreou, em abril daquele ano, o programa causou, como já demonstraram autores como Cássio Starling Carlos (2006), Jean-Pierre Esquenazi (2011), David Lavery (1995), entre outros, uma verdadeira revolução nas narrativas seriadas televisivas, especialmente em se tratando de uma emissora aberta, no caso a norte-americana $\mathrm{ABC}$. É claro que muito dessa repercussão ocorreu em razão do envolvimento de Lynch no projeto, justamente por conta de seu reconhecimento como cineasta independente e autoral, pela sua formação como artista plástico e por seu vasto conhecimento das vanguardas artísticas. O que fica evidente no conjunto de sua obra, mesmo em um produto de entretenimento televisivo, como Twin Peaks, é a constante experimentação. A combinação desse repertório nada convencional com uma narrativa tradicional de soap opera e série de investigação policial gerou repercussão imediata, além de alta audiência.

Twin Peaks tornou-se um sucesso e uma mania nos Estados Unidos, com uma pergunta espalhando-se rapidamente entre os telespectadores desde a exibição do episódio piloto: “Quem matou Laura Palmer?". O sucesso da primeira temporada fez com que o programa tivesse continuação e a segunda temporada teve início ainda no final daquele mesmo ano - até ser encerrada em 10 de junho de 1991, após perder público e entrar em declínio de audiência.

A trama se passava na pequena cidade madeireira de Twin Peaks, próxima à fronteira com o Canadá, onde foi encontrada morta, envolta por um saco plástico, a garota mais popular do lugar, a jovem Laura (Sheryl Lee, que também interpreta o papel da prima de Laura, Maddy Ferguson). Um agente especial do FBI, Dale Cooper (Kyle MacLachlan), é chamado para comandar as investigações, junto com o xerife local, Harry Truman (Michael Ontkean). A partir daí, tem início um verdadeiro desenrolar de fatos inusitados e sinistros e acontecimentos fantásticos. 
A partir de uma frase dita pelo (imagina-se) espírito de Laura Palmer ao agente Dale Cooper, quando ambos se encontram no Black Lodge, uma espécie de sala vermelha habitada por espíritos e réplicas (duplos), no último episódio da $2^{\mathrm{a}}$ temporada da série, em 1991, "eu o verei novamente em 25 anos", por muito tempo especulou-se uma volta de Twin Peaks, o que acabou ocorrendo em 2017, quando Lynch e Frost se reuniram novamente e realizaram o projeto Twin Peaks: O Retorno, uma espécie de minissérie em 18 episódios, todos roteirizados por Lynch e Frost e dirigidos por Lynch. O programa foi produzido e exibido pelo canal por assinatura Showtime nos Estados Unidos e teve distribuição internacional via Netflix. (A ideia inicial da dupla era que o novo programa fosse exibido em 2016, quando se completassem exatamente os 25 anos daquela frase, mas, por várias razões, isso não foi possível.)

Seria improdutivo tentar resumir o enredo e a trama de Twin Peaks: O Retorno em poucas linhas. Vale ressaltar, no entanto, que, além de retomar vários personagens da série original, outros tantos são introduzidos. A ação não se concentra mais somente em Twin Peaks e arredores, mas extrapola fronteiras estaduais, abarcando praticamente todas as regiões dos Estados Unidos, tanto em cidades pequenas como em grandes centros urbanos. E o mais importante: Lynch e Frost não embarcaram na onda nostálgica observada em inúmeras obras audiovisuais contemporâneas que retomam e resgatam os anos 80 e 90 simplesmente e desenvolveram uma nova temporada absolutamente livre de quaisquer amarras comerciais e mercadológicas, investindo numa proposta estilística e narrativa radical e inovadora, ainda mais caracterizada pela construção de uma atmosfera constante de pesadelo num tipo de ambientação que vai além daquela já experimentada nas duas primeiras temporadas.

Ambiência e atmosfera são fundamentais para se refletir sobre as complexas e misteriosas narrativas desenvolvidas por Lynch. Em várias de suas obras, percebe-se o emprego de elementos característicos do horror, dentro de uma proposta ancorada não somente nos gêneros cinematográficos, mas especialmente nos cinemas expressionista e surrealista. Pode-se observar isso, inclusive, em Twin Peaks: O Retorno. Dentre os vários aspectos observáveis no programa, alguns já presentes nas duas temporadas iniciais da série (1990-1991), o que mais chama atenção é justamente o estranhamento gerado pela sensação de incômodo causada a partir de situações cotidianas e cenas decorridas em ambientes comuns e familiares que se revestem de um caráter sinistro e assustador, próximo, portanto, daquilo que Freud chamou de inquietante ou estranho.

$\mathrm{Na}$ verdade, trata-se exatamente de uma das marcas autorais lynchianas, conforme já apontado por FERRARAZ (2003; 2005). Em praticamente todos os seus trabalhos audiovisuais, encontram-se vários exemplos dessas situações responsáveis por criar tal efeito perturbador. Lynch faz o convencional parecer anticonvencional; o familiar, estranho.

Essa presença do inquietante nas obras de Lynch também está relacionada diretamente com a forma como se inserem elementos incomuns e bizarros na 
narrativa, que introduzem o aspecto grotesco. $\mathrm{O}$ inquietante e o grotesco não se anulam; ao contrário, são complementares. No conto de Hoffmann, o efeito perturbador decorrente da transformação de algo familiar em estranho, associando-o à angústia e ao horror, está estreitamente ligado à presença de elementos grotescos. $\mathrm{O}$ mesmo acontece em todo o universo de Twin Peaks.

No conto de Hoffmann, outro fator que desperta o efeito de estranhamento ligado ao inquietante é a presença do doppelganger, ou o duplo. Não só o duplo humano, através do advogado Coppelius (vale ressaltar que, na história narrada pelo jovem Natanael, cujo pai era amigo de Coppelius, o advogado seria o próprio Homem da Areia), que ressurge na narrativa como Coppola, um vendedor de óculos, mas também o duplo mecânico, encarnado em Olímpia, uma garota bonita, por quem Natanael se apaixona, mas que não tem vida, por tratar-se, na verdade, de uma boneca, ou um autômato.

O duplo foi um tema marcante no Romantismo literário alemão e acabou aparecendo com frequência nos filmes expressionistas, servindo também ao cinema de horror clássico norte-americano, que, por sua vez, foi influenciado pelo expressionismo alemão.

Conforme observa Oscar Cesarotto, perante o fim inevitável, que é a morte, "Der doppelganger, a perturbadora aparição repentina do duplo, encarnada por esse outro que é o próprio sujeito", seria "a tentativa ilusória de superar, pela via do excesso, o nada a que somos condenados" (1996, p. 121-122). No entanto, esse Outro, o duplo, ganharia contornos sinistros, já que ele, segundo Cesarotto, "se converte (...) num mensageiro da morte, pois sua manifestação prenuncia o ocaso do sujeito" (CESAROTTO, 1996, p. 123).

Nos trabalhos do cineasta, tal figura irá se manifestar com frequência, seja real, imaginada ou desdobrada em várias personagens, que se completam e se enfrentam. São vários exemplos observados em toda a filmografia lynchiana, como: "Rita"/Camilla, vividas por Laura Elena Harring, e Betty/Diane, interpretadas por Naomi Watts, em Cidade dos sonhos (Mulholland Drive, 2001); Jeffrey Beaumont (Kyle MacLachlan) e Frank Booth (Dennis Hopper), em Veludo azul (Blue Velvet, 1986) - Frank, inclusive, diz, a certa altura, para Jeffrey, "Nós somos o mesmo!"; Fred Madison (Bill Pullman) e Pete Dayton (Balthazar Getty), em A estrada perdida (Lost Highway, 1997) - Fred, um virtuoso músico saxofonista que está preso por assassinar sua esposa, num certo dia some, e Pete, um mecânico, que tem o "melhor ouvido da cidade" para ajustar os carros, aparece em seu lugar na cela; ou ainda, em A estrada perdida, a ruiva Renee Madison, a mulher assassinada por Fred, e a loira Alice Wakefield, amante de Pete, ambas interpretadas por Patricia Arquette.

Tal tema, portanto, é muito trabalhado por Lynch e não poderia faltar no universo de Twin Peaks, onde o duplo também encontrou seu espaço. Na série original, por exemplo, o trabalho com o duplo é parte essencial da história. São muitas as figuras duplicadas: Leland Palmer (Ray Wise) e BOB (Frank Silva); Laura Palmer e sua prima Maddy Ferguson; o agente Cooper e seu doppelgänger. Isso se intensifica bastante em Twin Peaks: O Retorno. 
Outro fator que colabora para a atmosfera sinistra do conto de Hoffmann, a incerteza intelectual é também um dos recursos que Lynch utiliza em seus filmes. Em O homem da Areia, não fica claro para o leitor se as cenas descritas pelo protagonista Natanael realmente aconteceram ou não, se foram delírios de um apavorado menino ou uma sucessão de acontecimentos que devem ser considerados concretos, reais. O efeito de estranhamento se dá quando a distinção entre imaginação e realidade é extinta.

Por isso, os sonhos são tão importantes na obra de Lynch, assim como a questão temporal. Em Twin Peaks, o enigma do assassinato de Laura Palmer começa a se resolver quando Dale Cooper tem um sonho com o Black Lodge e vê, pela primeira vez, o espírito assassino $\mathrm{BOB}$, no terceiro episódio da primeira temporada. Em Twin Peaks: O Retorno, um dos novos personagens, William Hastings (Matthew Lillard), é preso acusado de assassinar uma mulher por causa das suas impressões digitais espalhadas pelo apartamento da vítima, apartamento em que ele nunca esteve, a não ser durante um sonho. São muitos e variados exemplos em que situações oníricas, na maioria das vezes em cenas cujos limites entre sonho e real estão insolitamente embaralhados, ocorrem no universo de Twin Peaks.

Assim como embaralhada é a linha temporal da história, tão enigmática para nós, espectadores, como para os próprios personagens. Isso se intensifica muito em Twin Peaks: O Retorno. Agora, não existe uma demarcação clara de tempo linear, com o dia e a noite se alternando. Perde-se a ideia de um dia por episódio da série original, que lembrava a estrutura de uma soap opera, misturada com série de mistério e investigação policial. Na nova temporada, tanto personagens como espectadores são jogados numa espiral fantasmagórica e sinistra em que as poucas respostas e demarcações se evaporam rapidamente como fumaça em meio ao turbilhão de acontecimentos fantásticos e perguntas enigmáticas.

Esse trabalho com a construção onírica e com a desconstrução temporal, muito próximo daquilo que Lynch chama de "lógica dos sonhos", acaba por reforçar um dos aspectos estudados por Freud em seu texto sobre o inquietante, justamente a questão da incerteza intelectual, servindo aqui como mais um elemento perturbador e causador de um sinistro estranhamento, gerador de angústia, tensão e horror no universo audiovisual de Twin Peaks.

\section{Considerações finais}

Procuramos demonstrar, através da análise de duas obras audiovisuais, o longa-metragem O Tempo do Lobo, de Michael Haneke, e a série televisiva Twin Peaks - O Retorno, de David Lynch (coescrita por Mark Frost), como o estranhamento pode ser observado no contexto do horror contemporâneo. Distintas em diversos aspectos estéticos e narrativos, tais obras se aproximam ao situar suas histórias no ambiente familiar e reconhecível, porém insólito e desconcertante, tornando-se, assim, propícias ao estudo comparativo em correlação ao conceito de inquietante proposto por Sigmund Freud. 
Para Freud, o estranho se relaciona ao familiar, ao próximo, ao conhecido, contribuindo, assim, para a compreensão do gênero em seu teor psicológico, como uma mistura de mistério e angústia, sendo catalizadores de medo e aversão, mas também de fascínio e atração.

Por fim, vale ressaltar que outras possibilidades de estudos comparativas entre as obras de Haneke e Lynch mostram-se atrativas e pertinentes, dando continuidade ao exercício analítico experimentado neste presente artigo. Basta lembrarmos das fitas de vídeo utilizadas como elementos geradores de suspense, angústia e medo tanto em A estrada perdida, de Lynch, como em Caché, de Haneke, para lançarmos as pistas de novas investigações.

\section{Referências}

BAZIN, André. An Aesthetic of Reality. In. What Is Cinema?, vol. 2, Berkeley: University of California Press, p. 28, 2004.

CABÚS, Lygia. A lenda dos 36 justos. Disponível em: <http://www.sofadasala.com/ lendas/lendados36justos.htm>. Acesso em: 28 nov. 2018.

CARLOS, Cássio Starling. Em tempo real: Lost, 24 horas, Sex and the City e o impacto das novas séries de TV. São Paulo: Alameda, 2006.

CARROL, Noël. A filosofia do horror ou paradoxos do coração. Campinas: Papirus, p. $183,1999$.

CESAROTTO, Oscar. No olho do Outro: "O Homem de Areia" segundo Hoffmann, Freud e Gaiman. São Paulo: Iluminuras, 1996.

DONNER, Wolf. The opposite of Hollywood. Londres: Amago, p. 35, 41, 2004.

ESNORRI. Voluspá. In. MOREIRA, Márcio A. A Edda poética: Parte I - Völuspá. Disponível em: <http://portal-dos-mitos.blogspot.com/2014/02/a-edda-poetica-parte-i-voluspa.htm>. Acesso em: 24 nov. 2018.

ESQUENAZI, Jean-Pierre. As séries televisivas. Lisboa: Texto \& Grafia, 2011.

FERRARAZ, Rogério. O cinema limítrofe de David Lynch. [Tese de doutorado] São Paulo: PUC, 2003.

. Para sempre, nos sonhos: Lynch, Hoffmann, Freud e o estranho. In: FABRIS, Mariarosaria; GARCIA, Wilton; CATANI, Afrânio Mendes (Org.). Estudos Socine de Cinema: Ano VI. São Paulo: Nojosa, 2005.

FREUD, Sigmund. O Inquietante. In. SOUZA, Paulo César (org.). Freud (1917- 
1920) Obras Completas v. 14: "O homem dos lobos" e outros textos. São Paulo: Companhia Das Letras, p. 269, 350-359, 2010.

FREY, Mattias. A cinema of disturbance: the films of Michael Haneke. In. PRICE, Brian; RHODES, John David (org.). On Michael Haneke. Detroit: Wayne State University Press, p. 98-113, 2010.

LAVERY, David (ed.). Full of secrets: critical approaches to Twin Peaks. Detroit: Wayne State University, 1995.

LODGE, Guy. The Times names Haneke's 'Caché' the decade’s best. In. In content. Disponível em: <http://www.incontention.com/2009/11/08/the-times-names-hanekes-cache-the-decades-best/>. Acesso em: 20 nov. 2018.

LÓPEZ, Augusto R. El cine de terror psicológico: La arquitetura de un falso género. Escribanía: Menizales, v. 14, n. 1, p. 42, 2016.

LOSILLA, Carlos. El cine de terror. Barcelona: Paidós, p. 87, 1993.

PRICE, Brian; RHODES, John David. On Michael Haneke. Detroit: Wayne State University Press, p. 113-115, 120, 2010.

TRÍAS, Eugênio. Lo bello y lo siniestro. Madri: Del Cardo, p. 39, 2001.

VOGEL, Amos. Of nonexisting continents: the cinema of Michael Haneke. In. Film Comment. vol. 32, n. 4, p. 73-75, 1996.

\section{Disquieting narratives of contemporary horror: the uncanny in Haneke and Lynch}

\section{Abstract}

The aim of this essay is to investigate the uncanny in contemporary horror through the analysis of two audiovisual works that fit into this context: Michael Haneke's The Time of the Wolf (Le temps du loup, 2003) and the television series Twin Peaks: The Return (2017), by David Lynch and Mark Frost. Distinct in a variety of stylistic, aesthetic and narrative aspects, such works come close to each other by situating their histories in the familiar and recognizable but unusual and disconcerting environment, thus becoming propitious to the comparative study in correlation with the concept of uncanny as proposed by Sigmund Freud.

\section{Keywords}

Horror; Uncanny; Haneke; Lynch; Freud. 